Materiales de Construcción

Vol. 67, Issue 325, January-March 2017, e113

ISSN-L: 0465-2746

http://dx.doi.org/10.3989/mc.2017.09015

\title{
Consolidation treatments applied to ceramic tiles: are they homogeneous?
}

\author{
D. Costa $\bowtie$, A.S. Leal, J.M. Mimoso, S.R.M. Pereira \\ Laboratório Nacional de Engenharia Civil, (Lisbon, Portugal) \\ $\triangle$ drcosta@lnec.pt
}

Received 27 October 2015

Accepted 14 July 2016

Available on line 30 January 2016

\begin{abstract}
The mass consolidation treatment of azulejos is necessary when ceramic biscuits show signs of disaggregation. Such treatment is often used as a complementary conservation technique to the reestablishment of weakened glaze-ceramic bonds.

In this research, two commonly used consolidants (ethyl silicate and acrylic resin) were tested on artisanal ceramic tiles via mass consolidation and the resulting impregnation profiles were evaluated. The results indicated that after consolidation, hard zones frequently formed due to localized consolidant concentration after the polymerization and curing processes. These inhomogeneous hard zones subsequently influenced the results obtained through conventional mechanical strength testing (i.e. flexural and compression), creating a false impression of success.

This research demonstrated that by using the Drilling Resistance Measuring System, impregnation characteristics such as penetration depth and distribution of consolidant could be observed that otherwise could not be discerned through the more common testing methods. As such, a more extensive evaluation of consolidation effects was achieved.
\end{abstract}

KEYWORDS: Ceramic; Mechanical properties; Characterization; DRMS; Consolidation

Citation/Citar como: Costa, D.; Leal, A.S.; Mimoso, J.M.; Pereira, S.R.M. (2017) Consolidation treatments applied to ceramic tiles: are they homogeneous? Mater. Construcc. 67 [325], e113. http://dx.doi.org/10.3989/mc.2017.09015.

RESUMEN: Tratamientos de consolidación aplicados en materiales cerámicos: ¿Son homogéneos? En la conservación de los azulejos alterados se utilizan productos con acción consolidante a fin de recuperar la cohesión del cuerpo cerámico disgregado. En este trabajo se investiga el efecto de la consolidación de dos productos muy utilizados en la práctica de la conservación de los azulejos (un silicato de etilo comercial y una resina acrílica), aplicados en un material cerámico artesanal. Los resultados obtenidos indican que pueden producirse zonas con resistencias mayores debido a la concentración local del producto $\mathrm{y}$, a la vez de un material consolidado homogéneo, resulta un material heterogéneo. Por otro lado, la existencia de estas zonas puede conducir a falsos resultados en los ensayos destructivos (resistencia mecánica a la flexión y compresión) utilizados frecuentemente en la evaluación de la acción de consolidación.

Se demuestra que mediante el uso de la resistencia a la perforación (DRMS) es posible definir las características, la distribución y el patrón de impregnación, los cuales no pueden ser observadas por los métodos comúnmente utilizados.

PALABRAS CLAVE: Cerámica; Propiedades mecánicas; Caracterización; DRMS; Consolidación

ORCID ID: D. Costa (http://orcid.org/0000-0003-4318-3348); A. S. Leal (http://orcid.org/0000-0001-6160-5837); J.M. Mimoso (http://orcid.org/0000-0003-4562-0898); S.R.M. Pereira (http://orcid.org/0000-0003-3070-743X)

Copyright: (C) 2017 CSIC. This is an open-access article distributed under the terms of the Creative Commons Attribution License (CC BY) Spain 3.0. 


\section{INTRODUCTION AND OBJECTIVES}

Glazed ceramic tiles (azulejos and related decorative plaques) are important cultural heritage resources in Spain, Portugal, Netherlands, Italy and many Islamic countries. Often, the conservation of such ceramics requires consolidation efforts.

The consolidation techniques used on glazed tiles are diverse and each effort must satisfy a different objective based on the most relevant repair and/ or degradation issues. Glaze loss is typically a substantial aspect in the conservation of such ceramics, although it is often also necessary to repair the ceramic body itself through consolidation. Saltladen walls can contaminate glazed tiles and cause powdering, crumbling, granular disintegration, scaling or flaking of the ceramic biscuit. Such symptoms typically justify the need for desalination and a consolidation action.

Mass consolidation of a ceramic body requires the use of different solutions and products from those used as adhesives to repair the glaze-biscuit connection. When mass consolidation is required, the consolidant must be able to penetrate the ceramic voids without creating rigid interfaces. This is a key parameter in the assessment of a successful consolidation effort and as such, it is important to evaluate the product penetration depth and distribution after polymerization and curing. The formation of sharp interfaces where the consolidated and non-consolidated substrates meet is considered a potentially harmful result. Differential behaviour of the two zones has the potential to produce, in the short or medium term, layer separation and consequential damage in the ceramic.

The level of cohesion is conventionally determined by measuring changes in mechanical resistance, for example, increases in mechanical resistance signify increases in cohesion. Destructive testing methods, such as compressive or bending strength tests, are usually used for this purpose $(1,2)$.

However, the consolidant often has difficulty in fully filling the voids and surface accumulations may occur as a result (in evaporation zones, for example). The extent and location(s) of accumulations cannot be detected with conventional tests, which rely on bulk analysis and are not depth discriminant.

Differential consolidation can lead to an overestimation of the consolidation effect since if an increase in the mechanical strength is measured, a potentially harmful result may be wrongly interpreted as a beneficial one.

SEM observation (or other and sophisticated techniques such as neutron tomography) can be used to assess the penetration and/or distribution of the product in depth (3). The development of a technique such as the Drilling Resistance Measuring System (DRMS), which measures hardness in depth, is a particularly relevant tool for assessing bulk consolidation efforts. Originally developed for stone conservation (4), DRMS has been used to characterize and analyse other materials (mortars or wood) and for other purposes where hardness in depth is relevant (such as determining salt distribution in depth). However, adequate adjustments of the drilling procedure and interpretation of the results is necessary to garner useful conclusions.

In this particular case, the objective was to evaluate the penetration characteristics of consolidation products applied to ceramic bodies as a first step in evaluating the consolidation action in these substrates. The following methods can also be used to characterize the resistance of the ceramic body itself, allowing for a comparison amongst different materials (5).

This research was conducted in order to clarify preliminary results which indicated an inhomogeneous distribution of consolidation treatments applied by capillarity (6). Micro-drilling tests were therefore performed in order to evaluate the distribution of a given consolidant in a ceramic similar to glazed tile biscuits.

\section{PRODUCTS AND METHODS}

The selection of consolidation products to be tested was based on three criteria: extensive use in practice (7); claimed high penetration depth; and partial compatibility with the ceramic body composition. Two products were ultimately chosen. Paraloid B $72^{\circledR}$, an acrylic resin, is currently the most commonly used consolidation material (7). Ethyl silicate-based products, including acid silicate esters such as TEOS (tetraethyl orthosilicate), are also frequently applied $(6,7)$ and claim high penetration depths. Paraloid B $72^{\circledR}$ was tested in 1, 3 and $5 \%(\mathrm{wt})$ dilution conditions, using acetone as a solvent. Tegovakon $\mathrm{V}^{\mathbb{R}}$ (TG), a TEOS, was tested in its ready-to-use state, already diluted in white spirit (for composition details see (8)).

The products were applied to the ceramic specimens through immersion, the method most commonly used in practice for mass consolidation in this field. It is also one of the methods recommended for laboratory testing to avoid the operator error which can occur during brush application (6).

The ceramic bodies selected for testing were semiartisanal tile biscuits produced by New Terracotta Lda. The physical characteristics of the biscuits are presented in Table 1.

Small pieces $\left(65 \times 30 \times 9 \mathrm{~mm}^{3}\right)$ were cut from larger square units $(130 \times 130 \times 9 \mathrm{~mm})$. The biscuit specimens were oven dried at $60^{\circ} \mathrm{C}$ for a minimum of 78 hours. The specimens used for TG consolidation were preconditioned in a humid environment $(\sim 90 \% \mathrm{RH})$ for three days in order to stabilize the mass.

The consolidation products were applied by immersion over a four hour period. The samples 
TABLE 1. Physical properties of ceramic bodies

\begin{tabular}{lccc}
\hline & $\begin{array}{c}\text { Mean } \\
\text { value }\end{array}$ & $\begin{array}{c}\text { Standard } \\
\text { deviation }\end{array}$ & $\begin{array}{c}\text { Number of } \\
\text { specimens }\end{array}$ \\
\hline Open porosity $(\%)^{*}$ & 37.6 & 0.2 & \\
Real density $\left(\mathrm{kg} \cdot \mathrm{m}^{-3}\right)^{*}$ & 1676 & 5 & 10 \\
Maximum water content $(\%)^{*}$ & 22.4 & 0.2 & \\
Bulk density $\left(\mathrm{kg} \cdot \mathrm{m}^{-3}\right)^{*}$ & 2686 & 10 & 10 \\
Bending strength $(\mathrm{MPa}) * *$ & 17.9 & 4.6 & 73 \\
\hline
\end{tabular}

Tested according to: * (9); ** (10)

were laid horizontally on rods in a vessel and the consolidants were added slowly, allowing for absorption in partial immersion conditions for the first ten minutes before being completely immersed. After cleaning with the proper solvent, the samples were weighed to determine the quantity of product absorbed. The specimens were kept in a closed container for approximately one month in order to provide for a controlled and slow evaporation process. After curing was complete, the specimens were oven dried (at $70 \pm 1{ }^{\circ} \mathrm{C}$ ), before being evaluated and tested.

Basic physical properties (Table 1) were measured before and after consolidation in order to evaluate material changes promoted by the consolidants. Ultrasonic pulse velocity testing was used along with DRMS to evaluate the mechanical properties and complement information provided by destructive testing. A Steinkamp Ultrasonic Tester BP-7 (from Germany) was used to determine the ultrasonic pulse velocity. The travel time of $\mathrm{P}$ waves was measured by direct mode using exponential transducers of $45 \mathrm{kHz}$ without any contact material. The ultrasonic pulse velocity was measured for all specimens both before and after consolidation.

The flexural strength was quantified as the highest stress at breakage, which is derived from the force applied at the time of rupture. Three-point bending tests were performed using a Gabbrielli CRAB424 machine according to the standard EN-ISO 10545.4 (10). Three ceramic samples per consolidant formulation $\left(65 \times 30 \times 9 \mathrm{~mm}^{3}\right.$ in size) were dried to a constant weight in a $40{ }^{\circ} \mathrm{C}$ ventilated oven and allowed to cool in a desiccator before testing. Drilling tests were then performed on tile fragments (remaining after the destructive bending tests) using a DRMS with a Sint Technology prototype. The following test conditions were used: $5 \mathrm{~mm}$ diameter drill bits $\left(\right.$ Fisher $\left.^{\mathbb{Q}}\right) ; 600 \mathrm{rpm}$ rotation speed; and $10 \mathrm{~mm} / \mathrm{min}$ penetration rate.

\section{THE USE OF DRMS ON CERAMICS}

DRMS (4) is a power drill with constant feed and a force transducer that measures thrust as a function of drilling depth. During testing, a $5 \mathrm{~mm}$ hole was made and the results, force and depth

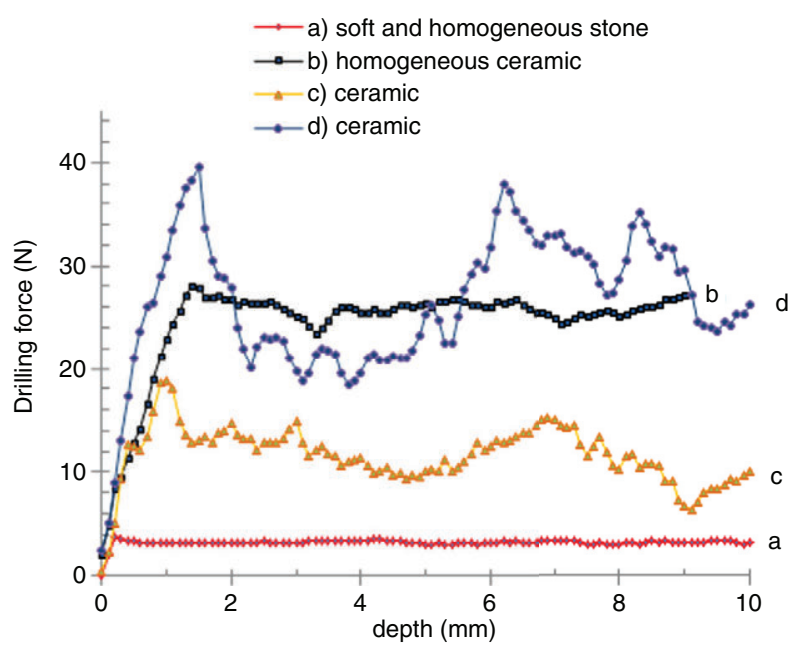

FIGURE 1. Examples of drilling resistance curves obtained on materials: a) soft and very homogeneous stone; b) homogeneous ceramic (used in this paper); c) and d) very heterogeneous old paving tiles with a superficial hard layer.

measurements, were registered by the system. The resulting output was a graph similar to that shown in Figure 1, which compares the homogeneous ceramic to soft and very homogeneous stone and heterogeneous paving tiles. In ceramics, intermediate hardness materials are often heterogeneous and typical drilling resistance curves are similar to (b) or (d) in Figure 1. However, the ceramic bodies used in this research can be considered quite homogeneous, as proven by the shape of the drilling resistance curves presented in Figure 2. In drilling resistance tests, the force increase in the first couple of millimeters depends on the type of drill bit used and the shape of the chisel edge. Instead of cutting through the surface immediately, the drill bit creates an indentation in the first couple of millimeters. The indentation promotes the rapid increase of force values observed on the graphs, which in turn identifies the hardness or resistance of the tested material, in this case, ceramics. Hard layers or zones can therefore be identified on drilling resistance curves, at any location or at any depth in the ceramic.

In addition to material characterization (except the $2 \mathrm{~mm}$ correspondent to the indentation in this case due to the type of drill bit), drilling resistance was used as a parameter to quantify the consolidation effect and identify the impregnation depth of each consolidant. However, drill bit wear when exists makes drilling resistance results more difficult to interpret. Nevertheless, the DRMS method is still considered very useful on ceramics or similar materials where hard grains (usually quartz) are present. The effect of drill bit wear depends not only on the material composition, but also on the texture and porosity of the test subject. For these reasons, it must be assumed that effects of drill bit wear are not universal and must be evaluated on a case-by-case basis and corrected when significant. 


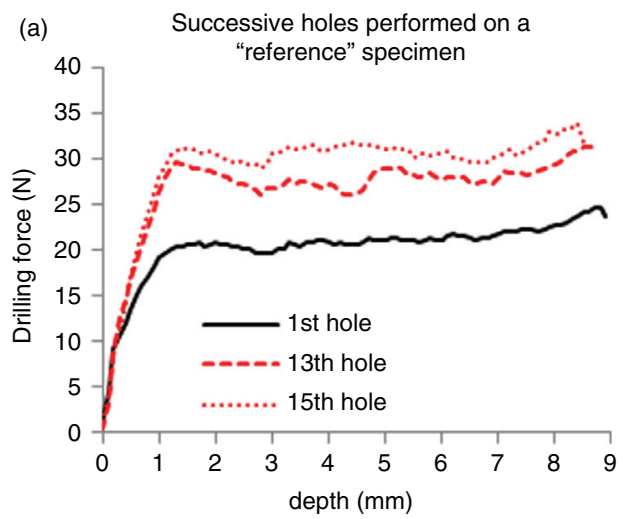

Effect of abrasivity on drilling test results measured on successive holes performed on ceramic material.

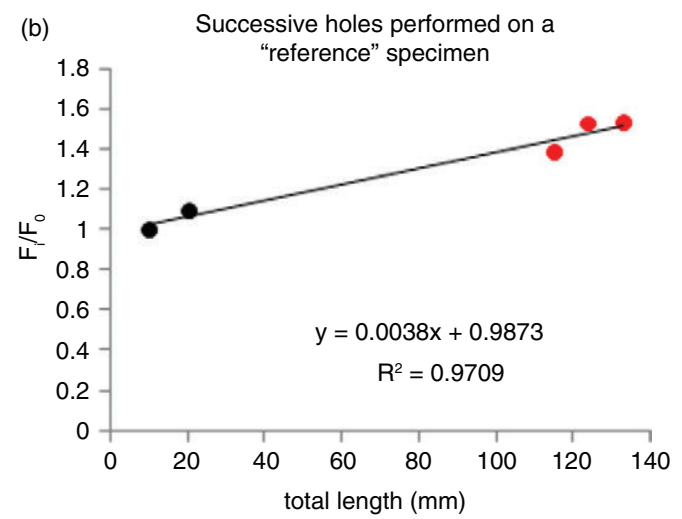

Abrasive law determined for a ceramic sample: "F" and "F," signify value of force at stage " 0 " and "i", respectively.

Figure 2. Drilling resistance on abrasive ceramic materials.

In order to evaluate the abrasive effect during drilling tests, successive holes were drilled in a reference material (a ceramic similar to that used for the consolidation tests) (Figure 2). The increase in drilling force from $20 \mathrm{~N}$ to $30 \mathrm{~N}$ in the first $\sim 2 \mathrm{~mm}$ (expressed in terms of mean values) is clearly due to the drill bit wear effect (the range of values may vary). In this case, a more compact material reached in the last $\sim 2 \mathrm{~mm}$ explains the increase in force. In other cases, such increases may represent dust accumulation which can be remedied by drilling over a previous pilot hole of smaller diameter (11).

To account for the increase in drilling force due to the abrasive effect, a calibration line was computed and the values corrected using a simple method (12) to eliminate the effect of drill bit wear on the results (Figure 2(b)). In this case, drilling resistance of the material was expressed by the mean values of drilling force (and the respective standard deviation) in the flat part of the curve $(2-7 \mathrm{~mm})$.

Past research showed that even in "hard conditions" of drilling resistance testing, results can be useful and relevant (13) in the evaluation of consolidation effects in old tiles. Ultimately, the micro-drilling assessments can be highly complex, mainly due to high heterogeneity and hard spots encountered in the first several millimetres of tile profiles of unknown origin.

\section{RESULTS AND DISCUSSION}

The consolidation action is the result of the quantity of consolidant retained inside the pore network after treatment. Ceramics are very porous with well-connected voids, and the quantity of consolidant liquid absorbed was about 3-4 g per ceramic specimen (TG absorption was higher than the Paraloid B72 ${ }^{\circledR}$ formulations). As such, the computed values of dry mass formed and retained after cure and polymerization are completely different with the two products (Table 2). However, the lower
TABLE 2. Quantity of consolidant liquid absorbed after treatment and product retained after consolidation.

\begin{tabular}{lrcrcc}
\hline & \multicolumn{2}{c}{ Liquid absorbed } & & \multicolumn{2}{c}{ Dry mass } \\
\cline { 6 - 6 } \cline { 5 - 6 } Products & $\mathbf{k g} / \mathbf{m}^{\mathbf{3}}$ & & $\mathbf{( \% )}$ & $\mathbf{k g} / \mathbf{m}^{\mathbf{3}}$ \\
\hline${\text { Tegovakon } \mathrm{V}^{\circledR}}^{\circledR}(\mathrm{TG})$ & 252 & & 7.8 & 127.2 \\
Paraloid B72 $^{\circledR}$ & $1 \%$ & 171 & & 0.3 & 4.7 \\
& $3 \%$ & 197 & & 0.7 & 11.0 \\
& $5 \%$ & 186 & & 0.8 & 11.5 \\
\hline
\end{tabular}

retention values of Paraloid $\mathrm{B} 72^{\circledR}$ may not be a negative result if homogeneous consolidant distribution can be achieved throughout a specimen.

The use of consolidation products also caused changes to the physical characteristics of the subjected materials, such as porosity and water absorption (Table 3 ). In all cases, the consolidants produced a slight hydrophobic effect in the ceramics (which may have been temporary) (8). The results are quite different for the TG versus Paraloid B72 ${ }^{\circledR}$ samples and appear to be linked directly to the quantity of consolidant formed after cure and polymerization.

Consolidants are expected to increase the mechanical resistance of an existing material. Therefore, in addition to determining bending strength, the ceramic specimens were subjected to ultrasonic velocity testing. Since ultrasonic velocity testing is non-destructive, it is a useful method for monitoring step-by-step changes (Table 4, Figure 3).

While there are clear differences in mechanical resistance between the TG and Paraloid B72 ${ }^{\circledR}$ treated ceramics, it is particularly noteworthy that within the Paraloid B72 ${ }^{\circledR}$ samples, changes in dilution from $3 \%$ to $5 \%$ did not considerably affect the ultrasonic and bending strength results (Table 4). On the contrary, the use of the $1 \%$ dilution resulted in lower values of both ultrasonic velocity and bending strength, although the actual results were greater than might have been expected based on Table 3 . 
TABLE 3. Open porosity and water content of ceramic bodies before and after consolidation.

\begin{tabular}{|c|c|c|c|c|c|c|c|}
\hline \multirow{2}{*}{\multicolumn{2}{|c|}{ Products }} & \multicolumn{3}{|c|}{ Open porosity $(\%)$} & \multicolumn{3}{|c|}{ Maximum water content (\%) } \\
\hline & & Before & & & Before & & \\
\hline \multicolumn{2}{|c|}{ Tegovakon $\mathrm{V}^{\circledR}$ (TG) } & \multirow{4}{*}{$37.8 \pm 0.2$} & $32.1 \pm 0.1$ & $(-13.1 \%)$ & \multirow{4}{*}{$22.0 \pm 1.1$} & $18.1 \pm 0.1$ & $(-17.7 \%)$ \\
\hline \multirow[t]{3}{*}{ Paraloid $^{\circledR}$} & $1 \%$ & & $37.4 \pm 0.5$ & $(\approx 0 \%)$ & & $22.3 \pm 0.4$ & $(\approx 0 \%)$ \\
\hline & $3 \%$ & & $36.7 \pm 0.5$ & $(-0.8 \%)$ & & $21.8 \pm 0.4$ & $(-0.7 \%)$ \\
\hline & $5 \%$ & & $36.5 \pm 0.2$ & $(-1.1 \%)$ & & $21.6 \pm 0.1$ & $(-1.5 \%)$ \\
\hline
\end{tabular}

TABLE 4. Mechanical resistance characteristics of ceramic bodies before and after consolidation.

\begin{tabular}{|c|c|c|c|c|c|c|c|c|c|c|}
\hline \multirow{3}{*}{\multicolumn{2}{|c|}{$\frac{\text { Products }}{\text { Tegovakon } \mathrm{V}^{\circledR}(\mathrm{TG})}$}} & \multicolumn{3}{|c|}{ Ultrasonic velocity (m/s) } & \multicolumn{3}{|c|}{ Bending strength (MPa) } & \multicolumn{3}{|c|}{ Drilling force $[2-7 \mathrm{~mm}](\mathrm{N})$} \\
\hline & & \multirow{2}{*}{$\begin{array}{c}\text { Before } \\
2960\end{array}$} & \multicolumn{2}{|c|}{ After } & \multirow[t]{2}{*}{ Before } & \multicolumn{2}{|c|}{ After } & \multirow[t]{2}{*}{ Before } & \multicolumn{2}{|c|}{ After } \\
\hline & & & 3630 & $(+17 \%)$ & & 21.5 & $(+25 \%)$ & & 30.5 & $(+45 \%)$ \\
\hline \multirow[t]{3}{*}{ Paraloid $^{\circledR}$} & $1 \%$ & 3230 & 3320 & $(+3 \%)$ & \multirow{3}{*}{17.2} & 18.0 & $(+5 \%)$ & \multirow{3}{*}{$21.1 \pm 1.0$} & 22.8 & $(+8 \%)$ \\
\hline & $3 \%$ & 3170 & 3330 & $(+6 \%)$ & & 19.3 & $(+12 \%)$ & & 24.6 & $(+17 \%)$ \\
\hline & $5 \%$ & 3150 & 3340 & $(+6 \%)$ & & 19.1 & $(+11 \%)$ & & 23.4 & $(+9 \%)$ \\
\hline
\end{tabular}
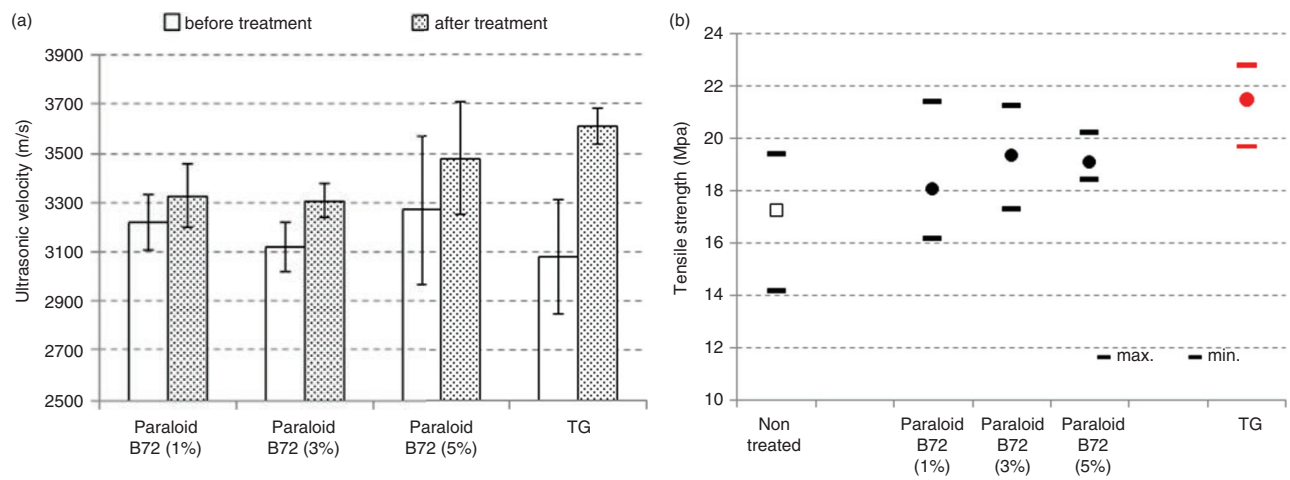

FIGURE 3. Ultrasonic velocity (on the left) and tensile strength (on the right) obtained on treated and non-treated ceramics consolidated with ethyl silicate (TG) and different formulation of Paraloid ${ }^{\mathbb{B}}$

Although the mean bending strength values for Paraloid $\mathrm{B} 72^{\circledR} 3 \%$ and $5 \%$ dilutions indicated a similar consolidation effect, particularly in comparison to the $1 \%$ dilution, the $5 \%$ concentration appeared to promote the most consistent tensile strength values (Figure 3).

In contrast, the drilling resistance results showed a complete discrimination between the four consolidation conditions, as can be clearly seen in the resulting graphs (Figure 4).

The original hardness of the non-treated ceramic body (NT) is defined by the curve of mean force values (and one standard deviation), using the same drilling conditions $(600 \mathrm{rpm}$ rotation speed, $10 \mathrm{~mm} /$ min penetration rate). For comparison, the nontreated curves are shown in black in each graph.

When the Paraloid B $72^{\circledR} 1 \%$ concentration was used, a homogeneous profile was obtained, with mean force values slightly higher than those of the nontreated ceramics (Figure 4(a)). Upon close inspection, it was possible to see a very small surface hardening effect in the first $\sim 1 \mathrm{~mm}$ of the profile, highlighted by a circle on the graph. In contrast, the Paraloid B $72^{\circledR} 3 \%$ and $5 \%$ dilution graphs clearly show a strong increase in resistance on the surface. In other words, a $2 \mathrm{~mm}$ deep hard zone was formed after consolidation with these concentrations (indicated with arrows). The actual hardness increase in these surface zones clearly depends on the consolidant concentration: for example, about $10 \mathrm{~N}(3 \%)$ or $20 \mathrm{~N}(5 \%)$.

The graphs indicate that when Paraloid B $72^{\circledR}$ was used, the product remained concentrated in the surface zones and it was difficult to see a clear sign of its presence inside of the ceramic (Figure 4(a)(c)). However, another slight force increase from $2-3.5 \mathrm{~mm}$ on the $5 \%$ dilution graph may be 

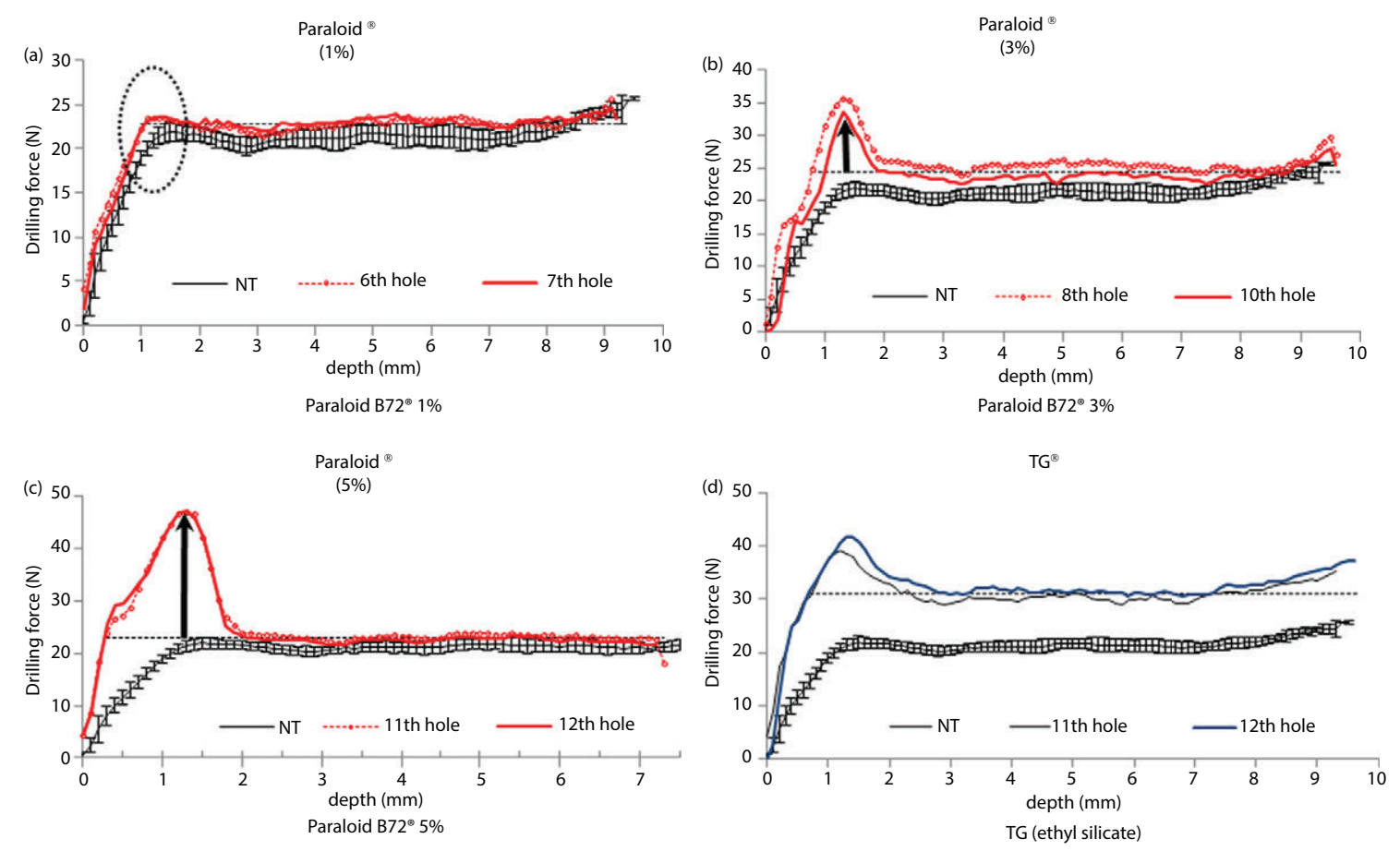

FIgURE 4. Drilling resistance curves for ceramic specimens treated with Paraloid B72® (a, b, c) and ethyl silicate (d).

attributed to the presence of consolidation product (Figure 4(b)).

The use of TG promoted a higher level of drilling resistance over the entire sample depth, although a harder surface zone is still evident (Figure 4(d)).

The increase in resistance on the specimen surfaces after consolidation is believed to be the result of consolidant drying and polymerization in this particular zone. In a previous study, similar patterns were detected in samples treated with the same consolidant formulations, even when no direct contact occurred between that surface and the liquid (6).

Ultimately, the use of DRMS for the characterization of ceramics and/or the evaluation of the efficacy of consolidants in such materials, can be not only time consuming, but also difficult due to the heterogeneity of the ceramic makeup and the wear effects of the drill bit used during testing. The ceramics tested in this research were quite homogeneous, albeit abrasive, and as a result the values of the drill resistance tests required correction to eliminate this effect.

\section{CONCLUSIONS}

High porosity materials are able to absorb large quantities of consolidant, a fact that is often seen as advantageous. In some circumstances, however, higher absorption can also limit effectiveness, in particular when considerable variations in the posttreatment physical properties cause internal stresses and possible fissures in the material.
The use of the drilling resistance measuring system for the characterization of ceramics treated with two types of consolidants (Tegovakon $\mathrm{V}^{\mathbb{B}}$ (TG) and Paraloid $\mathrm{B} 72^{\circledR}$ in three concentrations) produced meaningful and useful information that conventional methods were not able to do. Such results confirmed that DRMS can be successfully used to evaluate the distribution profile of consolidation products and is able to discriminate between different consolidation actions within ceramics.

The resultant data showed that both consolidants produce a hard zone close to the evaporation surface. However, TG (ethyl silicate) promoted a higher increase of the resistance throughout the depth of the ceramic, as opposed to Paraloid B72 ${ }^{\circledR}$, which showed little increase in the ceramic core.

The hard zones observed, in particular when Paraloid $\mathrm{B} 72^{\circledR}$ was used, are quite consistent and further investigation should proceed with the following objectives in mind: i) evaluate the potential risk of consolidation damage, in particular when salts remain in a ceramic; ii) find a method (such as delaying specimen drying by controlling various influencing conditions) to avoid an inhomogeneous consolidation, in particular when using Paraloid B $72^{\circledR}$ solutions.

In conclusion, these findings indicate the need to corroborate information gathered by the conventional tests used to evaluate consolidation effect and success, namely mechanical resistance and ultrasound velocity testing. The DRMS testing proved that the presence of resultant hard zones 
at the ceramic surface contribute to an increase in mechanical resistance after consolidation.

\section{ACKNOWLEDGEMENTS}

The authors acknowledge the financial support of Project CerAzul: PTDC/CTM-CER/119085/2010 for this research. The authors also thank Mr. Erik Ulrix from BIU International for supplying the Tegovakon $\mathrm{V}_{\mathrm{R}}$ sample.

The authors would like also to acknowledge the work and collaboration of Julie M. Rosen in the review of the paper.

\section{REFERENCES}

1. Constâncio, C.; Franco, L.; Russo, A.; Anjinho, C.; Pires, J.; Vaz, M.F.; Carvalho, A.P. (2010) Studies on polymeric conservation treatments of ceramic tiles with Paraloid B-72 and two alkoxysilanes. J. Appl. Polym. Sci., 116, 2833-2839. https://doi.org/10.1002/app.31743.

2. Vaz, M.F.; Pires, J.; Carvalho A. P. (2008) Effect of the impregnation treatment with Paraloid B-72 on the properties of old Portuguese ceramic tiles. J. Cult. Heritage 9 [3], 269-276. https://doi.org/10.1016/j.culher.2008.01.003.

3. Prudêncio, M.I.; Stanojev Pereira, M.A.; Marques, J.G.; Dias, M.I.; Esteves, L.; Burbidge, C.I.; Trindade M.J.; Albuquerque M.B. (2012) Neutron tomography for the assessment of consolidant impregnation efficiency in Portuguese glazed tiles (16th and 18th centuries). J. Archaeological Science 39, 964-969. https://doi. org/10.1016/j.jas.2011.11.010.

4. Tiano, P.; Filareto, C.; Ponticelli, S.; Ferrari, M.; Valentini, E. (2000) Drilling force measurement system, a new standardisable methodology to determine the "superficial hardness" of monument stones: prototype design and validation. Int. J. Restoration of Buildings and Monuments 6 [2], 115-132. https://doi.org/10.1515/rbm-2000-5461.

5. Fernandes, F.; Lourenço, P. (2007) Evaluation of the compressive Strength of ancient clay bricks using microdrilling. J. Mater. Civil. Eng, 19 [9], 791-800. https://doi. org/10.1061/(ASCE)0899-1561(2007)19:9(791).

6. Costa, D.; Leal, A. S.; Mimoso, J.M.; Pereira, S. (2015) Micro-drilling studies in azulejo consolidation. GlazeArch 2015, International Conference on Glazed Ceramics in Architectural Heritage, July 2015, LNEC, Lisbon.

7. Mendes, M.,T; Pereira, S.; Ferreira T.; Mirão, J.; Candeias, A. (2015) In Situ Preservation and Restoration of Architectural Tiles, Materials and Procedures: Results of an International Survey, Int. J. Conserv. Science, 6, 51-62. ISSN: 2067-533X.

8. Wheeler, G. (2005) Alkoxysilanes and consolidation of stone. Research in conservation. The Getty Conservation Institute, Getty Publications, Los Angeles, 2005. ISBN $0-89236-815-2$.

9. RILEM - Commission 25 PEM Protection et érosion des Monuments (1980) - "Essais recommandés pour mesurer l' álteration des pierres et évaluer l' efficacité des méthodes de traitement". Matériaux et Constructions, Bull. RILEM, 13 [75], pp. 216-220. ISSN 0025-5432.

10. NP EN ISO 10545-4: (1997) Ceramic tiles Part 4: Determination of modulus of rupture and breaking strength. CEN, Brussels, Belgium.

11. Mimoso, J.M.; Costa, D. (2006) The DRMS drilling technique with pilot holes. HWC 2006 - Heritage, Weathering and Conservation, Madrid, 19-26 June, 2, 651-655, 2006. ISBN 9780415412728.

12. Delgado Rodrigues, J.; Costa, D. (2004) A New Method for Data Correction in Drill Resistance Tests for the Effect of Drill Bit Wear. Int. J. Rest., 10 [3], 219-236. https://doi. org/10.1515/rbm-2004-5855.

13. Revez, M.J.; Costa D.; Rodrigues, J.D. (2008) Effects of TEOS-based consolidants on ancient paving tiles. Proceedings of Simpósio Internacional "Stone Consolidation in Cultural Heritage, 369-378, LNEC, Lisbon. ISBN 978-972-42-2135-8. 